\title{
PROFITABILITY, INVESTMENT, AND EFFICIENCY WAGES
}

\author{
JOÃO RICARDO FARIA
}

Received 13 October 2004

We examine a model that blends the neoclassical theory of investment with an intertemporal efficiency wage model with turnover costs. Investment decisions in capital are associated with the allocation of labor and the determination of efficiency wages. The model relates Tobin's $q$ to efficiency wages and, in particular, to the Solow condition. It provides a general framework to analyze firm's intertemporal choices of capital, labor and efficiency wages.

\section{Introduction}

The profitability of a firm is inherently connected with the choice of capital and labor. A variation in the firm's stock of capital affects the present value of profits, which makes the firm adjust the quantity of labor employed. In the same vein, a variation in the number of workers employed by the firm impacts in its profitability and leads the firm to adjust the stock of capital. Moreover, changes in the rental price of capital and/or in wages, by affecting the relative prices of labor and capital, have effects on the firm's profitability and led it to adjust its capital stock and/or labor employed. Therefore investment in capital and labor are related through firms profit expectations.

In the literature the dominant framework for analyzing firm behavior has been that of the neoclassical theory of investment, often referred to as the $q$ theory of investment. (The neoclassical approach due to Jorgenson [15] and the $q$ theory suggested by Tobin [26] were unified by Abel [1] and Hayashi [13].) In its standard formulation, this model relates the decisions of investment on capital to the ratio of the market value of new additional investment goods to their replacement cost, which is called Tobin's $q$. This simple framework, however, is unable to deal with firms' decisions concerning labor employment and wage setting.

Recent research has tackled this issue extending the model and its empirical applications to deal with labor allocation and other factors of production. Galeotti and Schiantarelli [10] show that a monopolistically competitive firm facing adjustment costs for capital and labor receives more empirical support than the standard version of $q$ type of investment models (see also, Shapiro [22]). The role of the wage setting process has been 
analyzed as well (e.g., Abowd [2]), in particular the impact of trade unions (e.g., Clark [7]). The importance of unions or any other wage setting process is that by affecting wages they in turn may affect labor productivity and the firm's profitability through rent appropriation, which has important consequences. (As stressed by Caballero and Hammour [6] rent appropriation can led to sub-utilization of resources, segmentation in factor markets, technological "sclerosis," and disequilibrium between job creation and destruction, these factors make recessions excessively sharp, and expansions run into bottlenecks.)

This paper examines firm's investment decisions in capital and labor in the presence of efficiency wages. Efficiency wage models have been used to explain numerous aspects of microeconomic labor market behavior, including segmented labor markets, persistent wage differentials for similar workers, and procyclical fluctuations of the quit rate, with macroeconomic implications such as involuntary unemployment and wage rigidity (e.g., Katz [16]; Gordon [11]).

The model analyzed in this paper blends the neoclassical theory of investment with an intertemporal model of efficiency wages with turnover costs (e.g., Hoon and Phelps [14]; Lin and Lai [17]; and Faria [8, 9]). The idea underlying the model is quite simple. In order to minimize turnover costs firms pay efficiency wages, since new workers are costly to find and to train. (The turnover theory of "efficiency" wages can be traced back to Phelps [20] and Stiglitz [25].) Moreover, when firms decide to invest in new capital they face adjustment costs that may involve training costs of new and old workers as well. As a consequence, investment decisions in capital are related to the allocation of labor and efficiency wages. The model provides a general framework to analyze the firm's intertemporal choices of capital, labor and wages. It allows us to relate Tobin's $q$ to efficiency wages, and, in particular, to the basic efficiency wage result, known as the Solow condition. (The Solow condition states that an optimizing firm sets its wage at the level at which the elasticity of work effort with respect to the real wage is unity (Solow [24]).)

The paper is structured as follows. The next section presents the basic model in which training costs are assumed to be independent of adjustment costs in capital. Section 3 drops this assumption and examines the model with non-separable adjustment-training costs. Section 4 introduces the stock of employees as a scale variable in the adjustmenttraining costs. Finally, the concluding remarks appear in Section 5.

\section{The basic model}

Production, employment and capital investment are carried out by many identical competitive firms. Workers are prone to quit in order to find a better pay job. Each of the firms seeks wage, hiring and investment policies to maximize the value of the firm's equity. The representative firm maximizes the present discounted value of its cash flows by choosing at each moment of time the current investment in capital $(I)$, the number of new workers $(h)$, and wage rate $(w)$ paid to its stock of employees $(N)$ :

$$
\operatorname{Max}_{w, h, I} \int_{0}^{\infty}\left[p F(K, e(w) N)-p_{I} I-p C(I, K)-p \Omega(h)-w N\right] e^{-\int_{0}^{t} r_{s} d s} d t
$$

where $e^{-\int_{0}^{t} r_{s} d s}$ is the discount factor, $r$ is the interest rate, and $p_{I}$ is the price of investment 
goods. The price of the produced good $p$ can be normalized to unity without loss of generality $[p=1]$, therefore $w$ can be taken as the real wage.

In the production function, $F(K, e(w) N)$, labor is measured in efficiency units: $E=$ $e(w) N$, where labor effort $e$, is an increasing function of the real wage: $e_{w}>0, e_{w w}<0$. (Given that the firm is price-taker in output and investment goods markets, it is necessary to explain why it is a wage-maker in the labor market. There are several explanations consistent with the efficiency wage hypothesis, firms may prefer to pay higher than the competitive market clearing wage in order to avoid shirking (Shapiro and Stiglitz [23]), or as a gift-exchange incentive (Akerlof [4]), or to minimize turnover costs (Salop [21]).) The production function has the usual properties: $F_{K}>0, F_{K K}<0 ; F_{E}>0, F_{E E}<0 ; F_{K E}>$ $0 ; F_{K K} F_{E E}-F_{K E}^{2}>0$, where $K$ is the capital stock.

The firm faces two types of costs, adjustment and training costs, relatively to their investment decisions on capital and labor. $C(I, K)$ is the installation or adjustment cost of capital, it is assumed to depend on the size of $I$ relative to $K$ (see Lucas [18]). Adjustment costs are an increasing and convex in $I: C_{I}>0, C_{I I}>0$, and decreasing and convex in $K: C_{K}<0, C_{K K}>0$, and $C(0, K)=0, C_{I K}<0$. Training costs. (In this model training costs are paid by firms. Workers acquire skills specifically for the firm. According to Acemoglu and Pischke [3] firms bear the costs of general training when labor market frictions compress the structure of wages.) $\Omega(h)$ are increasing and convex in the number of new hired workers: $\Omega_{h}>0 ; \Omega_{h h} \geq 0$. (Yashiv [27] considered general gross hiring costs over search and training costs. He tried many specifications for this function, including a convex one.)

The maximization problem is subject to two dynamic constraints, the capital accumulation equation:

$$
\dot{K}=I-\delta K,
$$

where $\delta$ is the rate of physical depreciation of the capital stock, and

$$
\dot{N}=h-Q(w) N
$$

which gives the change of employment per unit of time as the difference between the number of employees hired and the number of employed workers who quit. In line with the idea that efficiency wages decrease turnover costs, the quit rate $Q(w)$ is assumed to be a decreasing function of the real wage: $Q_{w}<0 ; Q_{w w}>0$.

To solve the representative firm's problem consider the current value Hamiltonian given by:

$$
H=F(K, e(w) N)-p_{I} I-C(I, K)-\Omega(h)-w N+\mu[I-\delta K]+\lambda[h-Q(w) N]
$$

where $\mu$ and $\lambda$ are the shadow prices of capital and job creation, respectively. $\mu$ is the present discounted value of additional future profits that are due to one additional unit 
of current investment, while $\lambda$ is the present discounted value of additional future profits that are due to one additional worker.

Given the assumptions above, the first order necessary and sufficient conditions for the representative firm's problem are the following:

$$
\begin{gathered}
H_{h}=0 \Longrightarrow \Omega_{h}=\lambda, \\
H_{I}=0 \Longrightarrow \mu=p_{I}+C_{I}, \\
H_{w}=0 \Longrightarrow F_{E} e_{w}=1+\lambda Q_{w}, \\
\dot{\mu}-r \mu=-H_{K}=-\left[F_{K}-C_{K}-\delta \mu\right], \\
\dot{\lambda}-r \lambda=-H_{N}=-\left[F_{E} e(w)-w-\lambda Q(w)\right], \\
\lim _{t \rightarrow \infty} e^{-\int_{0}^{t} r_{s} d s} \mu_{t} K_{t}=0, \\
\lim _{t \rightarrow \infty} e^{-\int_{0}^{t} r_{s} d s} \lambda_{t} N_{t}=0,
\end{gathered}
$$

plus (2.2) and (2.3).

Equation (2.5) shows that the marginal opportunity cost of training a new worker equals the shadow value of a trained worker. It states that the firm hires new workers to the point where the cost of creating a job and training a new worker equals the value of an additional worker. In (2.6) the cost of acquiring a unit of capital equals the purchase price plus the marginal adjustment cost. Thus condition (2.6) states that the firm invests to the point where the cost of acquiring capital equals the value of capital.

In (2.7) the marginal impact of wages on output equals one plus the marginal impact of wages in minimizing turnover costs. This condition gives a trade off between the real wage and the turnover cost. Equation (2.8) states that the shadow price of a unit of capital is equal to the present discounted value of the stream of marginal cash flow attributable to an additional unit of capital. Equation (2.9) has an analogous interpretation for an additional trained worker. Equations (2.10) and (2.11) are the transversality conditions.

By defining Tobin's marginal $q$ as the ratio of the market value of new additional investment goods to their replacement cost: $q=\mu / p_{I}$, one has by (2.6):

$$
q=1+\frac{C_{I}}{p_{I}}
$$

and by (2.8):

$$
\dot{q}-r q=-\frac{1}{p_{I}}\left[F_{K}-C_{K}\right]+q\left[\delta-\hat{p}_{I}\right]
$$

where $\hat{p}_{I}=\dot{p}_{I} / p_{I}$ is the rate of growth of the price of investment goods. 
The steady state equilibrium $\left[K^{\bullet}=N^{\bullet}=\lambda^{\bullet}=q^{\bullet}=0\right]$ of this model is given by (2.5), (2.12), and (2.7) plus the following equations:

$$
\begin{gathered}
\dot{K}=0 \Longrightarrow I=\delta K, \\
\dot{N}=0 \Longrightarrow h=Q(w) N, \\
\dot{q}=0 \Longrightarrow q=\frac{1}{p_{I}} \frac{\left[F_{K}-C_{K}\right]}{\left[r+\delta-\hat{p}_{I}\right]}, \\
\dot{\lambda}=0 \Longrightarrow F_{E} e(w)-w=\lambda[r+Q(w)] .
\end{gathered}
$$

The system of (2.5), (2.12), (2.7), (2.14), (2.15), (2.16), and (2.17) determine the optimal equilibrium values of seven unknowns: $I, K, w, h, N, q$, and $\lambda$.

One can study this system by examining two separate cases: (i) Linear training costs: $\Omega_{h}>0 ; \Omega_{h h}=0$; and (ii) Non-linear training costs: $\Omega_{h}>0 ; \Omega_{h h}>0$.

From (2.5), (2.12), and (2.7) one has:

$$
\varepsilon_{w} \equiv \frac{w}{e(w)} e_{w}=1+\Omega_{h}\left(Q_{w}-\frac{e_{w}}{e(w)}(r+Q(w))\right)
$$

where $\varepsilon_{w}$ is the effort-wage elasticity. A general result of this model, no matter whether training costs are linear or non-linear, is the following.

Proposition 2.1. The effort-wage elasticity is less than one. As a consequence, the Solow condition does not hold.

Proof. As $\Omega_{h}\left(Q_{w}-\left(e_{w} / e(w)\right)(r+Q(w))\right)<0$, this implies by $(2.18)$ that $\varepsilon_{w}<1$.

This result is in line with Akerlof and Yellen's [5] criticism that an effort-wage elasticity of unity ( $\varepsilon_{w}=1$, which is the Solow condition) is quite high because of additional costs such as shirking and turnover costs (e.g., Marti [19]). Because of these costs firms have an incentive to raise the efficiency wage above the one given by the Solow condition, which reduces the effort-wage elasticity below the unity.

By considering the first case in which training costs are linear, (2.18) determines the optimal equilibrium efficiency wage in the model, $w^{*}$.

Taking an explicit adjustment costs function: $C(I, K)=b I^{2} / K$, gives rise to the following proposition.

Proposition 2.2. With linear training costs the efficiency wage and Tobin's $q$ are independent.

Proof. Considering $C(I, K)=b I^{2} / K$, we have $C_{I}(I, K)=2 b I / K$ and substituting (2.14) into (2.12) gives the equilibrium optimal value of Tobin's $q$ :

$$
q^{*}=1+\frac{2 b \delta}{p_{I}}
$$


by considering (2.19) and (2.18), it is easy to see that $q^{*}$ does not affect $w^{*}$ and vice-versa, so there is no relation between $q^{*}$ and $w^{*}$.

This is an important result since it establishes that the efficiency wage is set independently of the shadow price of capital which is regarded as the main variable in determining investment decisions in capital.

When non-linear training costs are taken into account Proposition 2.2 does not hold. Instead, with non-linear training costs Tobin's $q$ affects the optimal equilibrium efficiency wages, as well as the optimal equilibrium levels of employment and capital stock.

This can be seen by the equations below. First, notice that by substituting (2.5) and (2.15) into (2.7) and (2.18) yields:

$$
\begin{gathered}
F_{E} e_{w}=1+\Omega_{h}(Q(w) N) Q_{w}, \\
\varepsilon_{w} \equiv \frac{w}{e(w)} e_{w}=1+\Omega_{h}(Q(w) N)\left(Q_{w}-\frac{e_{w}}{e(w)}(r+Q(w))\right) .
\end{gathered}
$$

Equations (2.20) and (2.21) together with (2.16) determine simultaneously the equilibrium values of $w, K$ and $N$. It is important to stress that when considering (2.20) and (2.16) the optimal value of $q$ is already determined by (2.19). This means that the system with non-linear training costs is block recursive, where the optimal $q, q^{*}$, is determined before $w, K$, and $N$. As a consequence, we can study the impact of $q^{*}$ on the remaining endogenous variables $w, K$, and $N$. This is presented in the following proposition.

Proposition 2.3. With non-linear training costs, an increase in Tobin's q leads to an increase in the equilibrium efficiency wage, employment, and capital stock.

Proof. From the comparative statics analysis of (2.16) and (2.20) one obtain:

$$
\begin{aligned}
& \frac{d w^{*}}{d q^{*}}=F_{E K} \Omega_{h h} Q\left[Q_{w}-\frac{e_{w}}{e}(r+Q)\right]|A|^{-1}>0, \\
& \frac{d N^{*}}{d q^{*}}=-F_{E K} \Theta|A|^{-1}>0, \\
& \frac{d K^{*}}{d q^{*}}=\left[F_{E E} \Theta-\Delta\right]|A|^{-1}>0,
\end{aligned}
$$

where:

$$
\begin{aligned}
\Theta & =\left\{\Omega_{h}\left[Q_{w w}+\left(\frac{e_{w}^{2}}{e}-\frac{e_{w w}}{e}\right)(r+Q)-\frac{e_{w}}{e} Q_{w}\right]-\varepsilon_{w w}+\Omega_{h h} Q_{w} N\left[Q_{w}-\frac{e_{w}}{e}(r+Q)\right]\right\}>0, \\
\Delta & =\left\{\Omega_{h h} Q\left[Q_{w}-\frac{e_{w}}{e}(r+Q)\right]\left[F_{E E}-\frac{\Omega_{h h}}{e_{w}} Q_{w} N-\frac{\Omega_{h}}{e_{w}} Q_{w w}+\Omega_{h} Q_{w} \frac{e_{w w}}{e_{w}^{2}}\right]\right\}>0, \\
|A| & =\frac{1}{p_{I}\left(r+\delta-\hat{p}_{I}\right)}\left\{\left[F_{K K} F_{E E}-F_{E K}^{2}\right] \Theta+F_{E K}^{2} \Omega_{h h} Q\left[Q_{w}-\frac{e_{w}}{e}(r+Q)\right]\right\}-\Delta<0 .
\end{aligned}
$$


Proposition 2.3 shows that in the steady state an increase in the value of equilibrium Tobin's $q, q *$, leads to an increase in the equilibrium stock of capital $K *$. At the same time the firm adjusts its quantity of capital to its work force, it has an incentive to hire new workers due to two factors. First, the introduction of new, more efficient capital goods is an important source of productivity change (see Greenwood et al. [12]), which increases the marginal productivity of labor. Second, because the additional capital demands more workers to operate them. Both factors shift up the demand for labor increasing employment and the efficiency wage.

As an illustration, consider a fall in the price of investment goods, which triggers a rise in equilibrium Tobin's $q$. This makes investment more attractive and the stock of capital rises, which shifts up the demand for labor leading to an increase in employment and efficiency wages.

So far the model with non-linear training costs provides us a direction of causality that runs from Tobin's $q$ to efficiency wages. This begs the question: Is this a general and robust result or does it depend on the assumptions of adjustment and training costs? Is not that possible to generate an inverse causality, that is, the efficiency wage affecting Tobin's $q$ ? The model in the following section answers these questions.

\section{Combining adjustment and training costs}

There is no reason for training costs to be independent of the capital stock and investment. That is, whenever the firm decides to hire new workers it has to train these workers to operate the existing capital stock and new machines as well. Furthermore, each additional unit of productive capital generates adjustment costs in relation to the existing capital stock. Therefore let us assume the following simple non-separable adjustmenttraining costs:

$$
C(I, K, h)=b h \frac{I^{2}}{K}
$$

Using (3.1) in firm's problem the first-order condition for $h$ is modified and in the steady state it yields:

$$
\lambda=b \delta^{2} K
$$

The effort-wage elasticity becomes:

$$
\varepsilon_{w} \equiv \frac{w}{e(w)} e_{w}=1+b \delta^{2} K\left(Q_{w}-\frac{e_{w}}{e(w)}(r+Q(w))\right)
$$

It is interesting to note that Proposition 2.1 holds in this case as well. That is, when training and adjustment costs are non-separable, the Solow condition does not hold and the efficiency wage is higher than the one consistent with the Solow condition. 
Taking the adjustment-training costs given by (3.1) into account, (2.20), (2.12), and (2.16) become:

$$
\begin{aligned}
F_{E} e_{w} & =1+b \delta^{2} K Q_{w}, \\
q & =1+\frac{2 b \delta}{p_{I}} h, \\
q & =\frac{1}{p_{I}} \frac{\left[F_{K}+b \delta^{2} h\right]}{\left[r+\delta-\hat{p}_{I}\right]} .
\end{aligned}
$$

From (3.6) and (3.5) using (2.15) it follows that:

$$
1+\frac{2 b \delta}{p_{I}} Q(w) N=\frac{1}{p_{I}} \frac{\left[F_{K}+b \delta^{2} Q(w) N\right]}{\left[r+\delta-\hat{p}_{I}\right]}
$$

The system of (3.3), (3.4), and (3.7) determines the equilibrium values of $K, N$, and $w$. This raises Proposition 3.1 below.

Proposition 3.1. An increase in the equilibrium efficiency wage leads to a fall in Tobin's $q$.

Proof. A rise in the equilibrium efficiency wage leads to a reduction in the equilibrium number of hired workers, $h^{*}$, by (2.15): $d h^{*} / d w^{*}=Q_{w} N<0$. In (2.15) the optimal value of efficiency wage, $w^{*}$, is already given. Since it was determined together with $N^{*}$ and $K^{*}$ by (3.3), (3.4) and (3.7). Thus it follows that an increase in the efficiency wage leads to a fall in Tobin's $q$ by (3.5): $d q^{*} / d w^{*}=\left(2 b \delta / p_{I}\right)\left(d h^{*} / d w^{*}\right)<0$.

The important message of Proposition 3.1 is that with non-separable adjustment and training costs, the direction of causality is inverted: it runs from the efficiency wage to Tobin's $q$. Moreover, in this model the efficiency wage is negatively related to Tobin's $q$. One could argue that this last result is due to linear adjustment-training costs in the number of new workers in (3.1). However, considering non-linear (quadratic) adjustment-training costs in $h$ does not change at all these results.

The models examined so far show that there are two possible results concerning Tobin's $q$ and the equilibrium efficiency wage: (1) they are not related; or (2) they are related in terms of causality. It remains to be analyzed weather Tobin's $q$ and the efficiency wage can be simultaneously determined in such a way to give a bi-directional causality between them. This exercise appears in the next section.

\section{A general adjustment-training costs function}

In the discussion of the non-separable adjustment-training costs function presented last section, the number of employed workers play no role. This seems to be an important omission. When the firm hires new workers it has to adapt them to the existing productive teams of workers in order to provide training and to allocate old and new capital per worker. This implies that the adjustment-training costs function has to incorporate 
the number of employees as a scale variable:

$$
C(I, K, h)=b \frac{h}{N} \frac{I^{2}}{K}
$$

Solving the model with this general adjustment-training costs function one has:

$$
\begin{gathered}
\lambda=b \delta^{2} \frac{K}{N} \\
q=1+\frac{2 b \delta}{p_{I}} \frac{h}{N} \Longrightarrow \frac{h}{N}=\frac{q-1}{2 b \delta} p_{I} \\
F_{E} e(w)-w+b \delta^{2} K \frac{h}{N^{2}}=\lambda[r+Q(w)] .
\end{gathered}
$$

By substituting (2.7), (4.2), and (4.3) into (4.4) yields:

$$
\varepsilon_{w} \equiv \frac{w}{e(w)} e_{w}=1+b \delta^{2} \frac{K}{N}\left(Q_{w}-\frac{e_{w}}{e(w)}(r+Q(w))\right)+\frac{e_{w}}{e} \frac{\delta K}{N} \frac{p_{I}(q-1)}{2} .
$$

From the analysis of (4.5) follows Proposition 4.1 below.

Proposition 4.1. With general adjustment-training costs the effort-wage elasticity is not necessarily less than one, and the Solow condition is a possible result. In general one has: $\varepsilon_{w} \geq 1$.

Proof. $\varepsilon_{w} \geq 1 \Leftrightarrow b \delta^{2}(K / N)\left(Q_{w}-\left(e_{w} / e(w)\right)(r+Q(w))\right)+\left(e_{w} / e\right)(\delta K / N)\left(p_{I}(q-1) / 2\right) \geq 0$.

Proposition 4.1 is a remarkable result, since even in the presence of turnover costs the Solow condition can be a possible result. One implication of Proposition 4.1 is that with general adjustment-training costs as given by (4.1) the efficiency wage is smaller than the efficiency wage found in the previous models.

By substituting (4.2) into (2.7) and (2.16) yields, respectively:

$$
\begin{gathered}
F_{E} e_{w}=1+b \delta^{2} \frac{K}{N} Q_{w}, \\
q=\frac{1}{p_{I}} \frac{\left[F_{K}+b \delta^{2} Q(w)\right]}{\left[r+\delta-\hat{p}_{I}\right]} .
\end{gathered}
$$

Finally by substituting (2.15) into (4.3) one has:

$$
q=1+\frac{2 b \delta}{p_{I}} Q(w)
$$

The examination of the system formed by (4.5), (4.6), and (4.7), generates the following proposition.

Proposition 4.2. With general adjustment-training costs the equilibrium efficiency wage and Tobin's q are determined simultaneously. 
Proof. It is easy to see that the system of (4.5), (4.6), and (4.7) determines the equilibrium values of $K, N, w$, and $q$ simultaneously.

The consequence of Proposition 4.2 is that there is bi-directional causality between Tobin's $q$ and the efficiency wage in the steady state equilibrium.

\section{Concluding remarks}

This paper has presented a model that blends the neoclassical theory of investment with an intertemporal efficiency wage model with turnover costs. This framework allows the study of the relationship between Tobin's $q$ and the efficiency wage, and its implications for the allocation of capital and labor.

In a simple set up where training costs of new workers are independent of adjustment costs of capital, it is shown that the effort-wage elasticity is less than one, that is, the Solow condition does not hold. In addition, for the case of linear training costs, there is no relationship between Tobin's $q$ and the efficiency wage. However, when non-linear training costs are taken into consideration, Tobin's $q$ affects the efficiency wage. Specifically, an increase in Tobin's $q$ leads to an increase in the optimal stock of capital, labor employment and in the efficiency wage.

When the training costs are assumed to be non-separable from adjustment costs of capital the effort-wage elasticity is still less than one, and the Solow condition does not hold either. As opposed to the previous case, however, with non-separable costs the efficiency wage affects Tobin's $q$. The model shows that an increase in the equilibrium efficiency wage leads to a fall in Tobin's $q$.

Finally, by considering general non-separable adjustment-training costs in which the stock of employees enters as a scale variable, the model generates a simultaneous determination of Tobin's $q$ and efficiency wages. Moreover, the effort-wage elasticity can be equal or greater than the unity, which means that the Solow condition can hold in this case.

\section{Acknowledgments}

I would like to thank, without implicating, one anonymous referee and an associate editor for helpful comments.

\section{References}

[1] A. B. Abel, Investment and the Value of Capital, Garland, New York, 1979.

[2] J. M. Abowd, The effect of wage bargains on the stock market value of the firm, American Economic Review 79 (1989), no. 4, 774-800.

[3] D. Acemoglu and J.-S. Pischke, The structure of wages and investment in general training, Journal of Political Economy 107 (1999), no. 3, 539-572.

[4] G. A. Akerlof, Labor contracts as partial gift exchange, Quarterly Journal of Economics 97 (1982), no. 4, 543-569.

[5] G. A. Akerlof and J. L. Yellen, Introduction, Efficiency Wage Models of the Labor Market (G. A. Akerlof and J. L. Yellen, eds.), Cambridge University Press, Cambridge, 1986, pp. 1-21.

[6] R. J. Caballero and M. L. Hammour, The macroeconomics of specificity, Journal of Political Economy 106 (1998), no. 4, 724-767. 
[7] K. B. Clark, Unionization and firm performance: the impact on profits, growth, and productivity, American Economic Review 74 (1984), no. 5, 893-919.

[8] J. R. Faria, Supervision and effort in an intertemporal efficiency wage model: the role of the Solow condition, Econom. Lett. 67 (2000), no. 1, 93-98.

[9] - The effects of taxes on labour in a dynamic efficiency wage model, Jpn. Econ. Rev. 55 (2004), no. 3, 286-297.

[10] M. Galeotti and F. Schiantarelli, Generalized Q models for investment, Rev. Econom. Statist. 73 (1991), no. 3, 383-392.

[11] R. J. Gordon, What is new-Keynesian economics?, Journal of Economic Literature 28 (1990), no. 3, 1115-1171.

[12] J. Greenwood, Z. Hercowitz, and P. Krusell, Long-run implications of investment-specific technological change, American Economic Review 87 (1997), no. 3, 342-362.

[13] F. Hayashi, Tobin's marginal $q$ and average q: a neoclassical interpretation, Econometrica 50 (1982), no. 1, 213-224.

[14] H. T. Hoon and E. S. Phelps, Macroeconomic shocks in a dynamized model of the natural rate of unemployment, American Economic Review 82 (1992), no. 4, 889-900.

[15] D. W. Jorgenson, Capital theory and investment behavior, American Economic Review 53 (1963), no. 2, 247-259.

[16] L. F. Katz, Efficiency wage theories: a partial evaluation, NBER Macroeconomics Annual 1 (1986), 235-275.

[17] C.-C. Lin and C.-C. Lai, The turnover costs and the Solow condition in an efficiency wage model with intertemporal optimization, Econom. Lett. 45 (1994), no. 4, 501-505.

[18] R. E. Lucas, Adjustment costs and the theory of supply, Journal of Political Economy 75 (1967), no. $4,321-334$.

[19] C. Marti, Efficiency wages: combining the shirking and turnover cost models, Econom. Lett. 57 (1997), no. 3, 327-330.

[20] E. S. Phelps, Money-wage dynamics and labor-market equilibrium, Journal of Political Economy 76 (1968), no. 4, 678-711.

[21] S. C. Salop, A model of the natural rate of unemployment, American Economic Review 69 (1979), no. $1,117-125$.

[22] M. D. Shapiro, The dynamic demand for capital and labor, Quarterly Journal of Economics 101 (1986), no. 3, 513-542.

[23] C. Shapiro and J. E. Stiglitz, Equilibrium unemployment as a worker discipline device, American Economic Review 74 (1984), no. 3, 433-444.

[24] R. Solow, Another possible source of wage stickiness, Journal of Macroeconomics 1 (1979), no. 1, $79-82$.

[25] J. E. Stiglitz, Alternative theories of wage determination and unemployment in LDC'S: the labor turnover model, Quarterly Journal of Economics 88 (1974), no. 2, 194-227.

[26] J. Tobin, A general equilibrium approach to monetary theory, Journal of Money, Credit and Banking 1 (1969), no. 1, 15-29.

[27] E. Yashiv, Hiring as investment behavior, Review of Economic Dynamics 3 (2000), no. 3, 486522.

João Ricardo Faria: Department of Economics and Finance, University of Texas Pan American, 1201 West University Drive Edinburg, TX 78541, USA

E-mail address: jfaria@panam.edu 


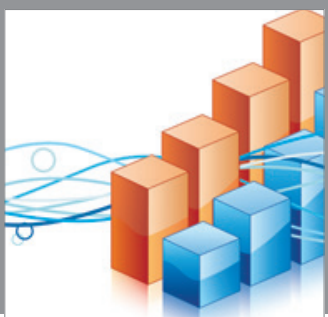

Advances in

Operations Research

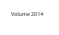

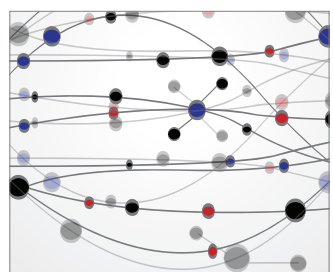

\section{The Scientific} World Journal
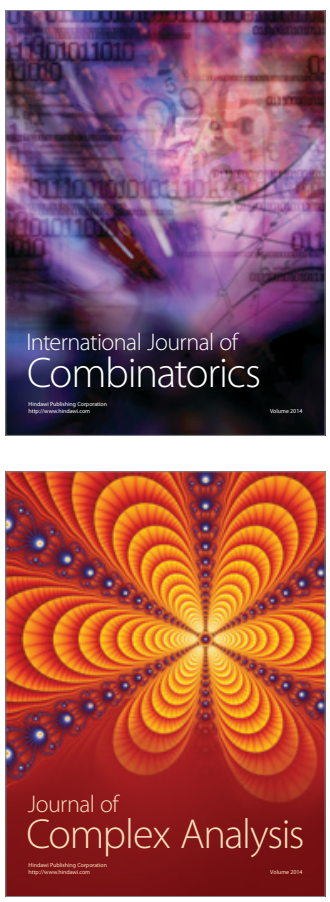

International Journal of

Mathematics and

Mathematical

Sciences
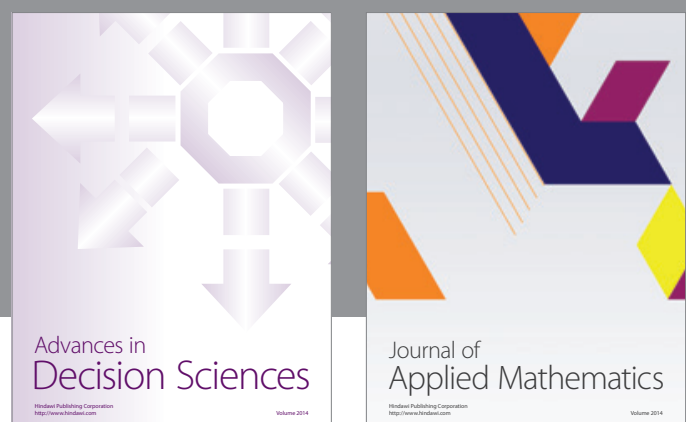

Journal of

Applied Mathematics
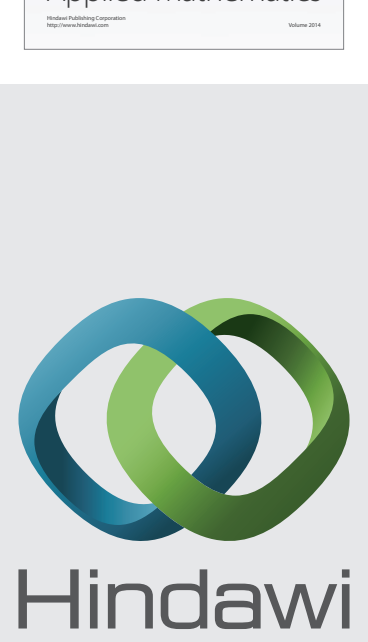

Submit your manuscripts at http://www.hindawi.com
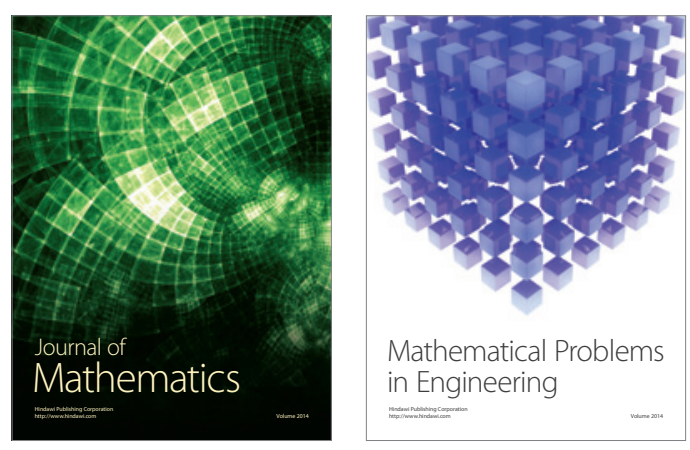

Mathematical Problems in Engineering
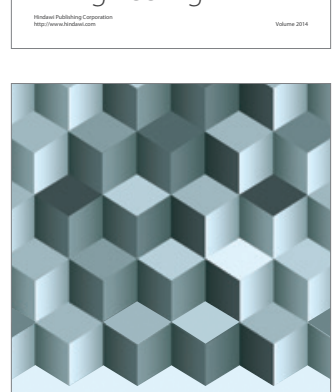

Journal of

Function Spaces
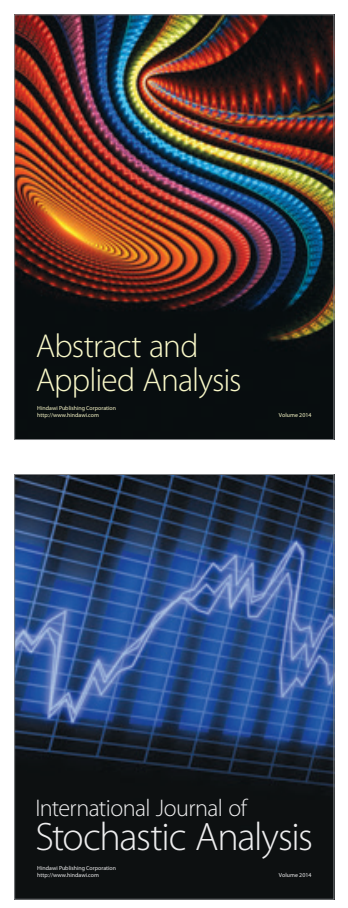

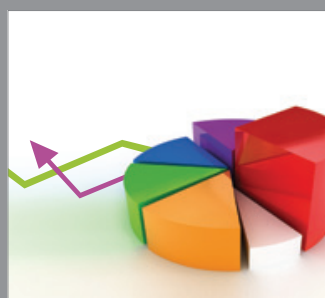

ournal of

Probability and Statistics

Promensencen
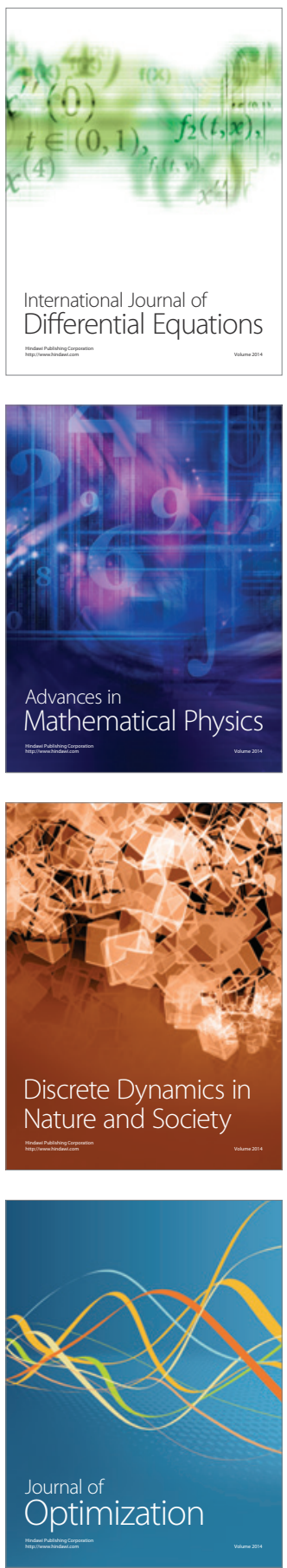